\title{
Achieving energy reduction by applying passive cooling strategies in a hot arid region: a case study of the UAE
}

\author{
D. Tachouali \& H. Taleb \\ Faculty of Engineering, British University in Dubai, UAE
}

\begin{abstract}
As Dubai is considered one of the world's fastest growing metropolises, it is important to mention that it was ranked the first for having the highest ecological footprint due to rapid development and environmental consequences.

Passive cooling buildings offer thermal and visual comfort for their inhabitants by interacting with natural resources such as the sun and wind to extend the limit of achieving a comfortable environment without having to use mechanical means like air-conditioning, which also helps in reducing energy consumption and $\mathrm{CO}_{2}$ emissions.

The aim of this study is to investigate the effect of passive cooling strategies on a building project in Dubai at the design stage in order to get the highest efficiency in terms of passive cooling while avoiding overheating conditions. This is done by adopting a simulation study approach using energy simulation software IES (Integrated Environmental Solutions) to evaluate the actual effect of passive cooling strategies on the building.

Once the results for both cases are collected using the IES software, the study will discuss the results of each strategy and compare it with the base case to reach a final conclusion and also show the strategies that have the biggest impact on indoor space temperatures and help reduce total energy consumption.

Keywords: United Arab Emirates, IES, passive cooling, aquaponics, green walls, cross ventilation, innovative strategies, double skin facade.
\end{abstract}

\section{Introduction}

The world is worried about its future and climate change is a global concern, therefore many rating systems (such as LEED, Green Globes, BREEAM, 
ASHREA Standards and others) have been established to identify solutions to reduce the $\mathrm{CO}_{2}$ emissions that cause the global warming and achieve a sustainable life and healthy environment.

According to the IEA [1], the UAE was ranked first for the highest ecological footprint due to rapid development and its environmental consequences.

\section{UAE FOOTPRINT BY LAND TYPE}

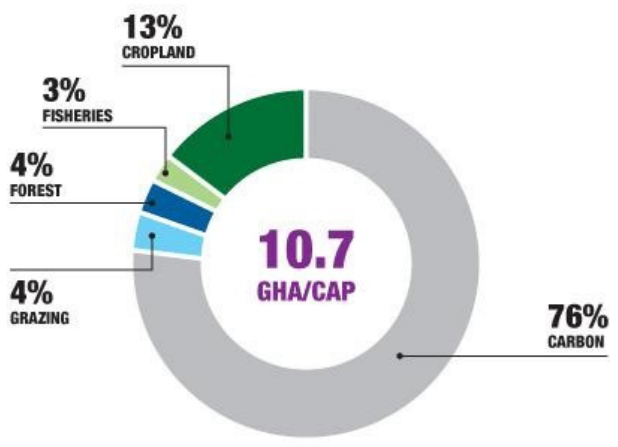

Figure 1: UAE footprint by land type.

Passive cooling buildings offer thermal and visual comfort for their inhabitants by interacting with natural resources such as the sun and wind to extend the limit of achieving a comfortable environment without using mechanical cooling which helps reduce energy consumption and $\mathrm{CO}_{2}$ emissions (Santamouris and Asimakopoulos [2]).

The aim of the study is to investigate the effect of passive cooling strategies on a project in Dubai at the design stage, getting the highest efficiency rate for passive cooling and avoiding overheating conditions.

\section{Methodology}

As the aim of the study is to investigate the effect of cooling strategies on the project, it will investigate six passive cooling strategies: natural ventilation thermal insulation - double skin façade - green walls - aquaponic system and a daylighting system (solar tubes).

By referring to a literature review, the study will apply strategies to the project and compare with a base case and a passive case by adopting a simulation study using the energy simulation software IES to see the actual effects of passive cooling strategies on the building. Once the results for both cases have been produced using the IES software there will be a discussion of the results of each strategy and comparisons with the base case to reach a final conclusion. 


\section{Dubai climate data}

Dubai has a hot arid climate, in summer the temperature can reach $45^{\circ} \mathrm{C}$ in August according to (Figure 2), while in winter the average monthly temperature can fall to $19.8^{\circ} \mathrm{C}$ in January.

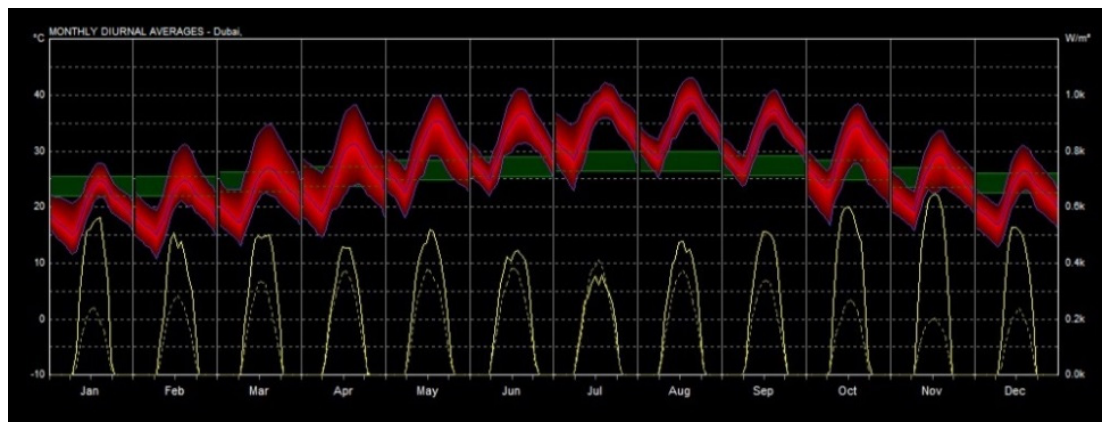

Figure 2: Monthly average temperature in Dubai.

It is worth mentioning that the temperature can exceed thermal comfort levels in winter - up to $29.7^{\circ} \mathrm{C}$ in December - and that the prevailing wind will play a big role in cross ventilation analysis as a passive cooling strategy.

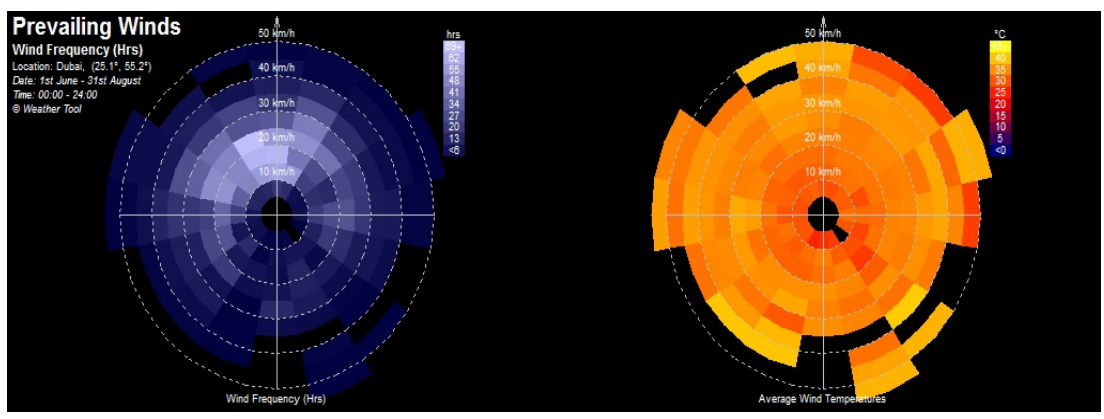

Figure 3: Wind temperature and direction in Dubai.

\section{Case study (Eco Friendly Hub)}

\subsection{Site analysis}

The location of the case study is Al Mizhar in Dubai, a typical residental area that consists of diffirent type of buildings (flats and villas), (Figure 4) shows the location of Al Mizhar in Dubai to show the neighbouring boundaries.

The location is distinguished by several different factors, it covers a $(25 \mathrm{~m} \mathrm{x}$ $25 \mathrm{~m})$ plot and main streets are located on the east and south sides of the project. 
To the north, the site is boarded by trees and by villas from the wes. The south is populated by a parking area serving a shopping mall.

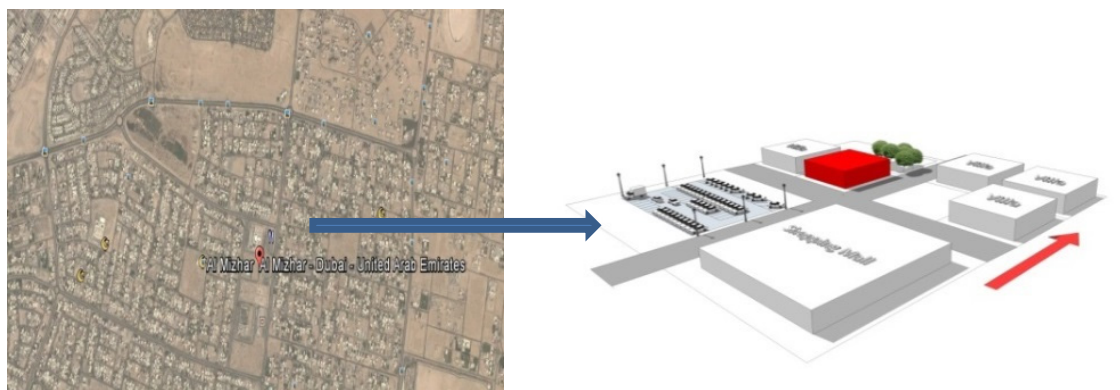

Figure 4: The location of the case study in Al Mizhar (source: authors).

(Figure 5) shows the sun's path through different seasons which is required to design shading devices and also to determine the location of the openings.
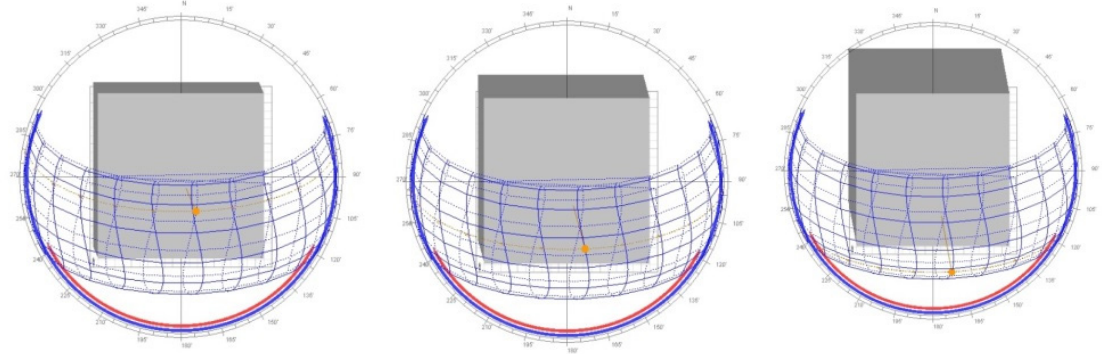

Figure 5: The sun's path in summer, spring and winter.

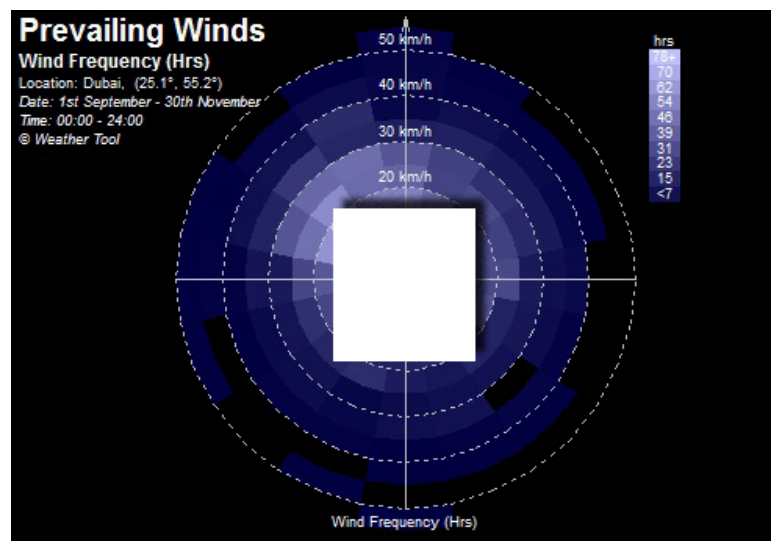

Figure 6: Prevailing winds' direction. 


\subsection{Design concept}

Changes in the environment are impacting on natural resource availability and increases in energy costs are all challenges for future generations; human actions have a big impact on the environment, therefore, an initiative step is required to show responsibilty. This can be started by educating ourselves and the community by promoting sustainable practice and as a result (the Eco Friendly Hub) is an initiative towards better life quality without harming the surrounding environment.



Figure 7: Concept diagram showing the development of the design concept.

\subsection{Description of the project}

The Eco Friendly Hub is $893 \mathrm{~m}^{2}$, it consists of two storeys linked with a central core, the building responds to the site environment through location of several functions, one of the interesting functions is the MIT energy club, which is used to convert mechanical effort into electricity, Stark [3] explained how treadmills can provide 700 watts per minute which equals the energy consumption of eight light bulbs, if an athletic spends an hour on the treadmill everyday, the machine will produce $255 \mathrm{KW}$.h per year.
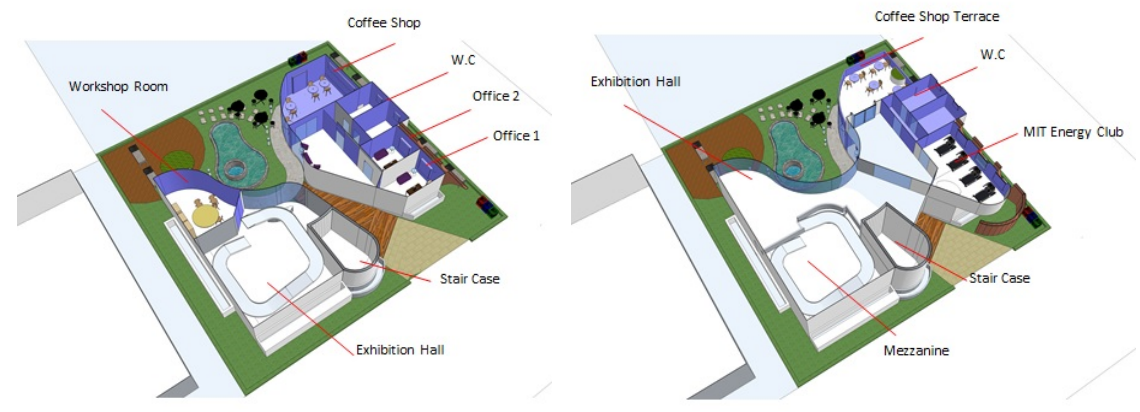

Figure 8: Ground floor and first floor plan of the base case. 

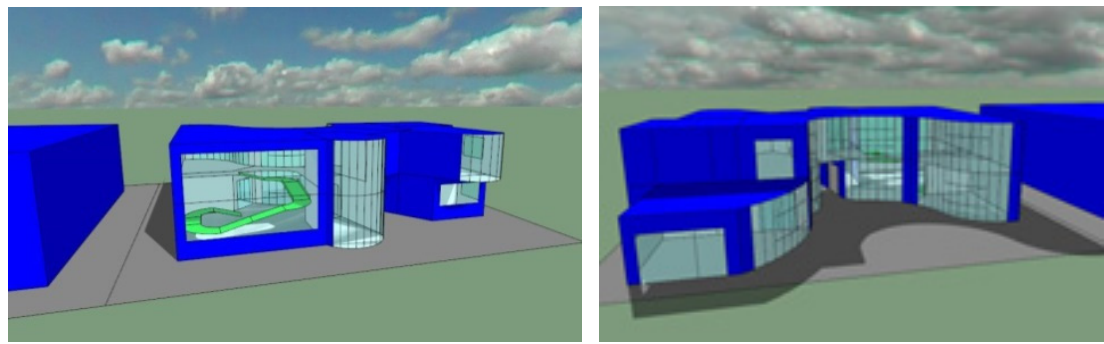

Figure 9: 3D perspective of the building for south and north elevations.

The structure of the base case building is a light brick for exterior walls and single glaze for windows, Openings were avoided on the west elevation out of respect for the neighbouring villa.

The surrounding landscape of the project was used to serve different functions, such as a coffee shop and workshop, this creates a visiual connection between the indoor and outdoor environment. Furthermore, the big area of glazing in the north elevation helps in creating a visiual connection as well, having a good view over the vegetated area.

\section{Passive cooling strategies: simulation study and discussion}

The project uses IES VE software for simulation to compare the results with the base case and show at the end total energy consumption and $\mathrm{CO}_{2}$ emissions for both cases.

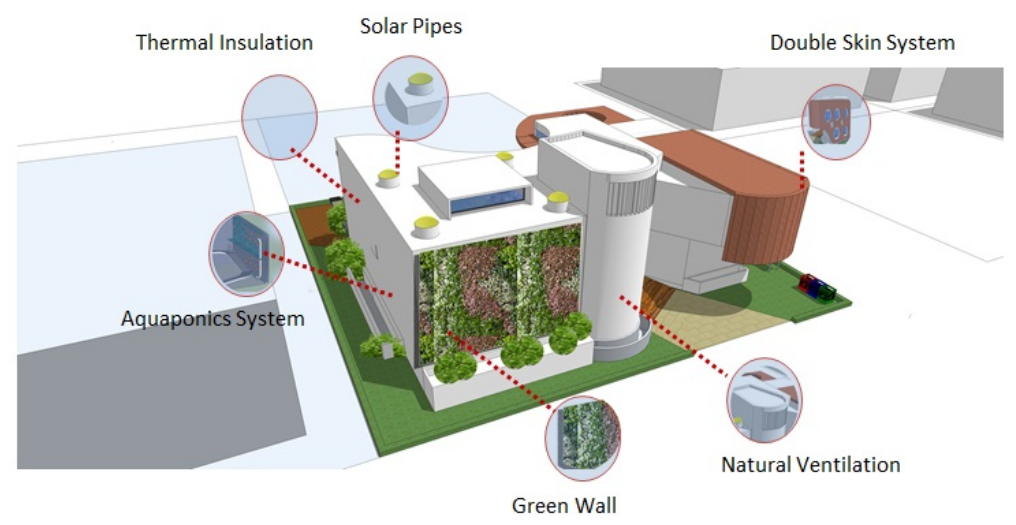

Figure 10: Passive cooling strategies applied to the passive case.

\subsection{Natural ventilation}

\subsubsection{Cross ventilation}

Referring to the literature review, Kwork and Grodzik [4] defined cross ventilation as an efficient way to reduce energy consumption when it is applied 
in cold seasons (December,January,February); this project will study the impact of cross ventilation on the MIT energy club.

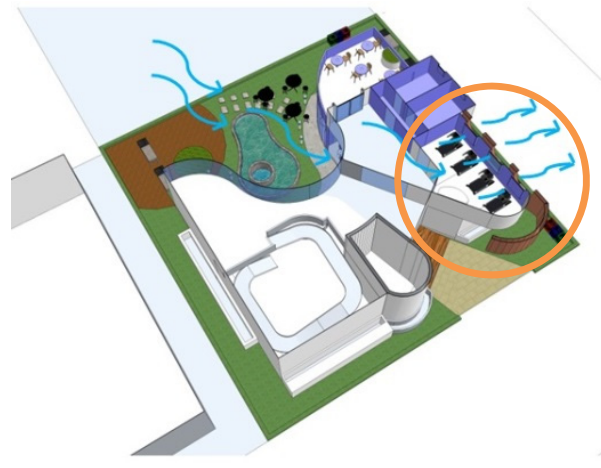

Figure 11: Cross ventilation detail.

(Figure 12) shows how the speed of the wind increased. When the wind flew in the building from the north west, wind flow was around $3301 / \mathrm{S}$ and when it arrived at the MIT energy club it reached to $418 \mathrm{l} / \mathrm{S}$.
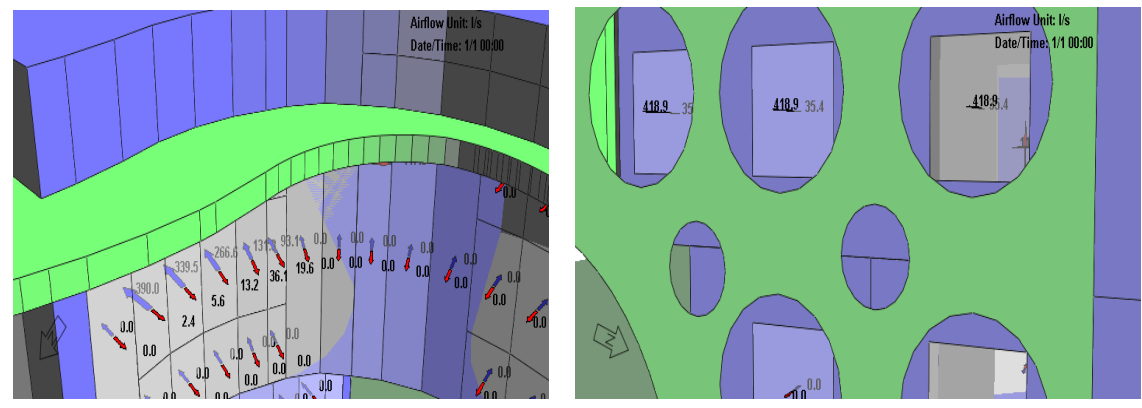

Figure 12: The airflow crossing in and out of the building.

Cross ventilation has many advantages, in addition to reducing the air temperature, it helps to bring fresh air in to the inner space and get rid of exhaust air.

\subsection{Double skin system}

The double skin system works as a secondary skin with a low-emittance inner surface to reduce radiant solar gain, the cavity between the outer skin and the building skin $(50 \mathrm{~cm}-100 \mathrm{~cm})$ helps in creating continuous cross ventilation (Brown and Dekay [5]); one of the goals of using a double skin system is to give the building an aesthetic appeal and approach the aim of protecting the exterior wall from solar gain. To show effect of the DSF, this project studied solar exposure for the base case and the passive case as is presented in (Figure 13). 

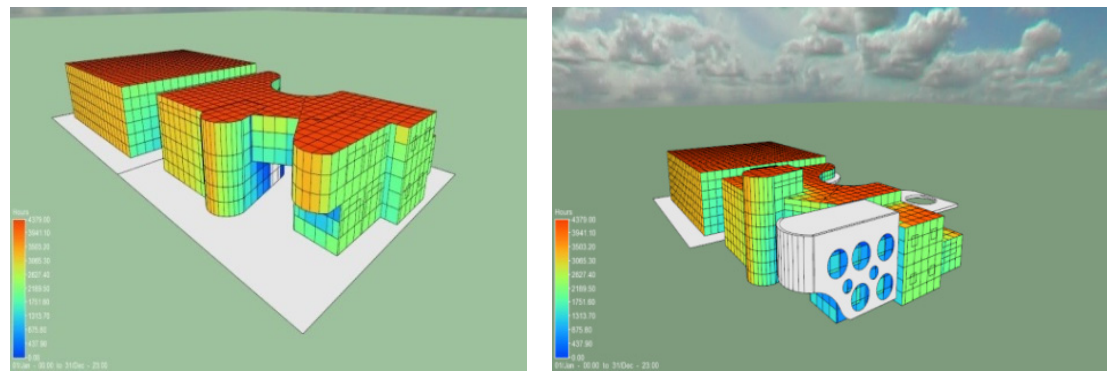

Figure 13: Solar exposure for the base and passive cases.

As a result of the solar exposure calculation, the readings for solar exposure dropped from 2189 hours to 875 hours.

\subsection{Aquaponics system}

The main reason for using the aquaponic systemis is to irrigate the green wall and reduce water demand. Furthermore, it will be used as a thermal mass to insulate the south elevation. Armstrong [6]; Liu and Baskaran [7] found that green envelopes are a good source for reflecting $75-90 \%$ of the solar radiant in summer (Figure 14) ensured the successful effect of the fish tank in insulating the exterior wall, which is integrated with the green wall and the insulation material as one unit.

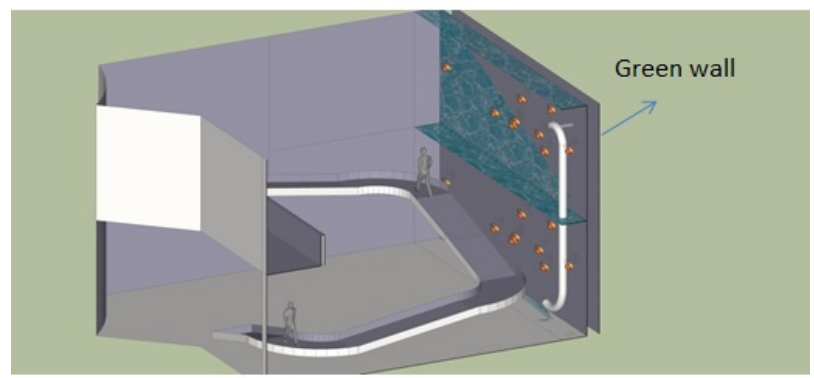

Figure 14: Cross-section of aquaponics system.

In the base case, indoor temperature exceeded outdoor temperature due to solar gain. On the other hand, the passive case achieved the level of thermal comfort on the $15^{\text {th }}$ March.

\subsection{Solar pipes}

The solar pipe system solved the problem of lighting the deep exhibition hall (Figure 17) shows the radiance comparision between the base and the passive cases within the exhibition hall; Asad [8] studied how the solar pipes can affect 
the performance of employees in high rise office buildings in the UAE and found that solar pipes can achieve the required lux level inside deep offices and helped in improving their performance at work. The challenge was how to maintain a flux level between 300 to 500 lux.

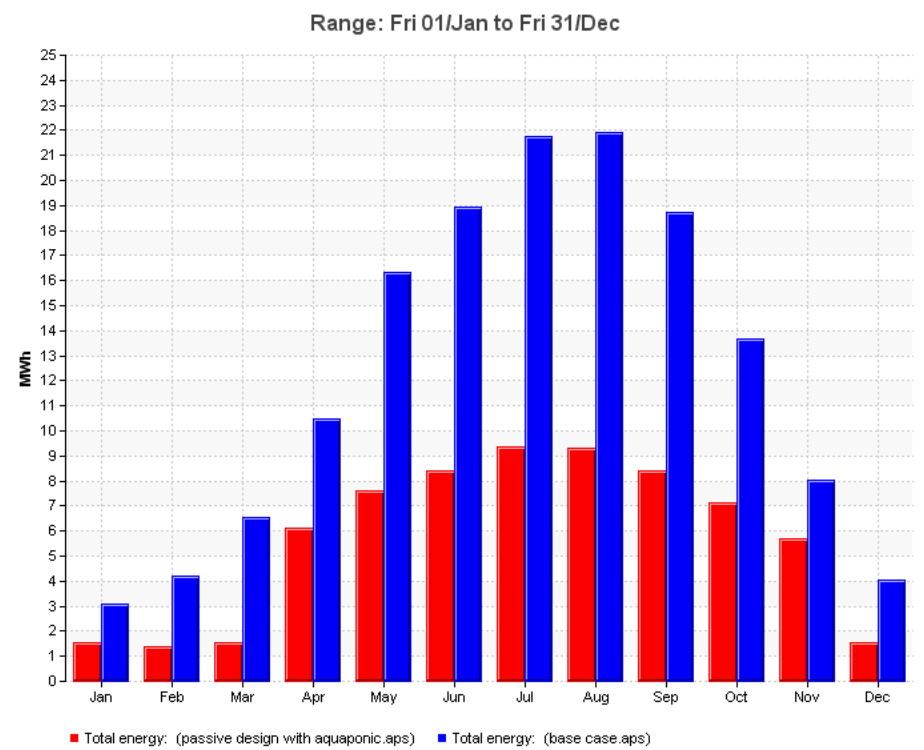

Figure 15: Total energy consumption (IES VES 2014).



Figure 16: Indoor air temperature: passive and base cases. 

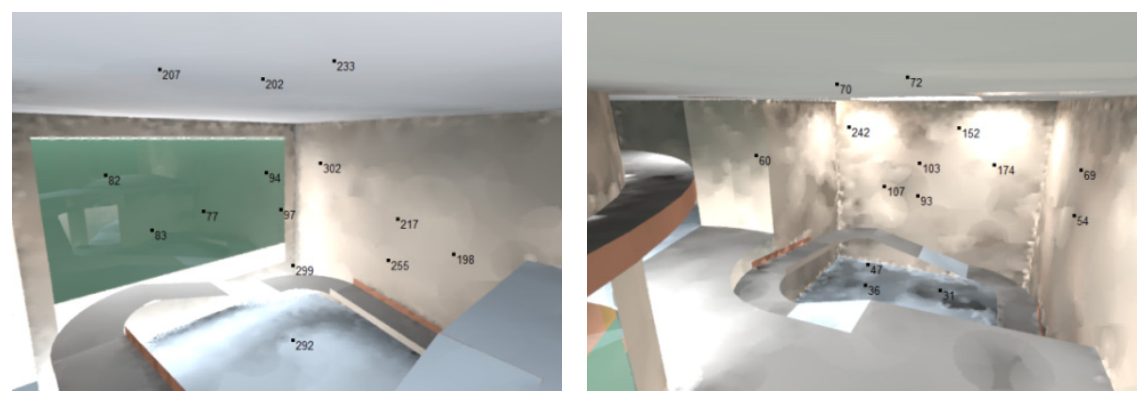

Figure 17: Radiance in the passive and base cases.

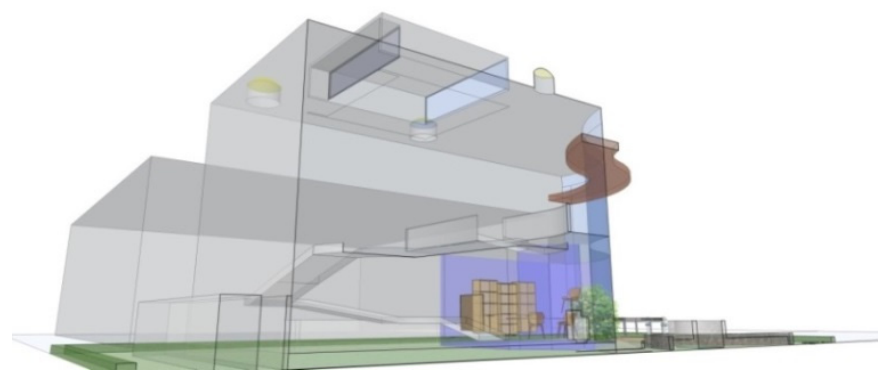

Figure 18: Cross-section showing the solar pipes applied in the passive case.

$\begin{array}{lcc} & \text { The Base Case } & \text { The Passive Case } \\ \text { Date } & & \\ \text { Jan 01-31 } & 1.5411 & 3.0747 \\ \text { Feb 01-28 } & 1.3919 & 4.1942 \\ \text { Mar 01-31 } & 1.5411 & 6.5514 \\ \text { Apr 01-30 } & 18.1603 & 10.4636 \\ \text { May 01-31 } & 36.8977 & 16.3309 \\ \text { Jun 01-30 } & 47.6933 & 18.9104 \\ \text { Jul 01-31 } & 54.8673 & 21.7788 \\ \text { Aug 01-31 } & 56.7712 & 21.9341 \\ \text { Sep 01-30 } & 48.9206 & 18.7215 \\ \text { Oct 01-31 } & 29.049 & 13.646 \\ \text { Nov 01-30 } & 13.0891 & 8.0508 \\ \text { Dec 01-31 } & 1.5411 & 4.035 \\ \text { Summed } & 311.4637 & 147.6911 \\ \text { total } & & \end{array}$

Figure 19: Total energy consumption. 


\section{Conclusion}

In a passive cooling project, the main aim is to protect the building from heat gain and direct exposure to the sun, it is important to mention that some passive cooling strategies gettoo affected by the climate - such as in cross ventilation to show a good impact on indoor space temperature .

The aquaponics system was an innovative solution to solve the problem of irrigating the green walls and reducing solar gain.

The IES VE software helped as a the main tool to analyse the effect of the passive strategies chosen even though it was difficult to give an accurate effect of the green wall system. This was solved by giving the $U$ value to the soil. In addition to this, the fish tank effect was achieved by giving it the properties of water. Overall, by using passive cooling strategies, $47 \%$ of energy was saved.

\section{Acknowledgement}

The authors would like to thank "MUSTADAMA Ltd. Sustainable Solutions" in Masdar City-Abu Dhabi for sponsoring this paper to be presented in the "Sustainable Development and Planning Conference" held in Istanbul in May 2015.

\section{References}

[1] International Energy Agency. Tracking Industrial Energy Efficiency and $\mathrm{CO}_{2}$ Emissions. [Accessed 1 March 2014]. Available at: http://www.iea.org/ publications/freepublications/publication/name,3708,en.html

[2] Santamouris, M., Asimakopoulos, D., Passive Cooling of Buildings. James \& James Science Publisher Limited, London, 1996.

[3] Stark. (2011). Could We Use Exercise Machines as Energy Sources? [Accessed 2 February 2014]. Available at: http://www.engineering.mit.edu/ ask/could-we-use-exercise-machines-energy-sources

[4] Kwok \& Grandzik. The Green Studion Handbook. NY: Taylor and Francis, 2011.

[5] Brow and Dekay. Sun, Wind and Light architectural Design strategies. Canada: John Wiley and Son, Inc., 2001.

[6] Armstrong. Living Enriched Multi Unit Flat Developing with Aquaponic System Integration. University of Detroit Mery [Accessed 8 March 2014]. Available at: http://archive.udmercy.edu:8080/handle/10429/674

[7] Liu, K.; Baskaran, B. Thermal performance of green roofs through field evaluation. Proceedings for the First North American Green Roof Infrastructure Conference, 2003.

[8] Asad. Investigating The Effect of Light Pipes as Daylight Strategy on Employee Performance levels in High Rise Office Buildings in The UAE, 2009. 